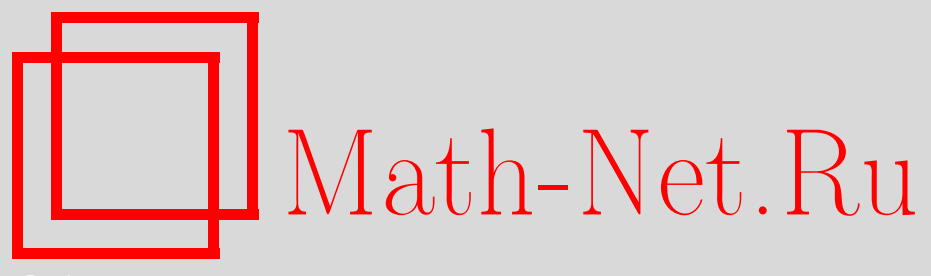

М. С. Агранович, А. И. Аптекарев, А. Л. Афендиков, Н. Д. Введенская, М. И. Вишик, С. Г. Гиндикин, М. М. Маламуд, Б. П. Панеях, Е. В. Радкевич, В. М. Тихомиров, А. Р. Ширикян, Леонид Романович Волевич (некролог), УМH, 2007, том 62, выпуск 6, 157-160

DOI: https://doi.org/10.4213/rm8543

Использование Общероссийского математического портала Math-Net.Ru подразумевает, что вы прочитали и согласны с пользовательским соглашением http: //www.mathnet.ru/rus/agreement

Параметры загрузки:

IP : 54.198 .64 .247

26 апреля 2023 г., $17: 40: 24$

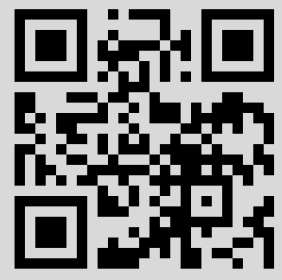




\section{Леонид Романович Волевич}

26 апреля 2007 года после тяжелой болезни скончался Леонид Романович Волевич.

Леонид Романович родился в Москве 11 июля 1934 г. Его отец был известным врачом-невропатологом, мать - переводчиком и преподавателем зарубежной литературы. В 1952 г. он поступил на Механико-математический факультет МГУ, где с 4-го курса занимался в семинаpe О.А. Олейник. В 1957 г. он закончил мехмат и поступил в аспирантуру к К. И. Бабенко в Отделение прикладной математики Математического института им. В. А. Стеклова. В 1960 г. Л. Р. Волевич защитил кандидатскую диссертацию “Локальные свойства решений систем дифференциальных уравнений в частных производных" и остался работать в отделе К.И. Бабенко в организованном М. В. Келдышем Институте прикладной математики. В этом институте

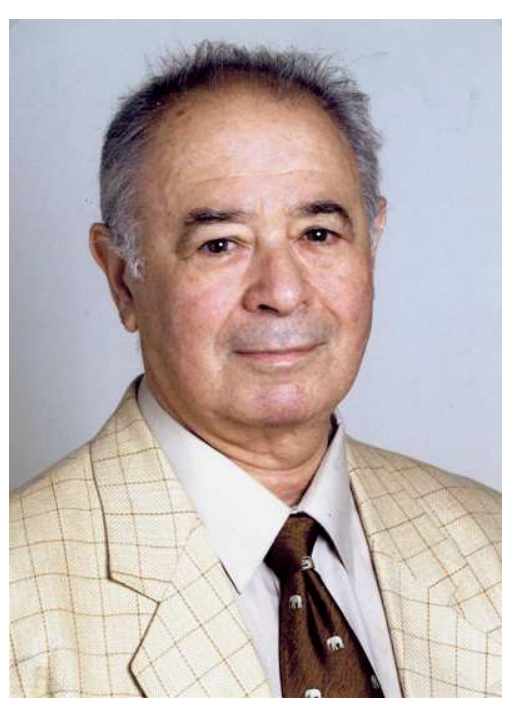
Леонид Романович проработал всю жизнь, с 1997 г. в должности главного научного сотрудника. В 1971 г. Л. Р. Волевич защитил докторскую диссертацию "Исследования по неоднородным псевдодифференциальным операторам (вопросы регулярности решений, задача Коши)".

Л. Р. был постоянным активным участником университетского семинара М. И. Вишика с момента его организации. В 1965 г. Правление Московского математического общества назначило О. А. Олейник главным редактором “Трудов ММО”, а Леонида Романовича - заместителем главного редактора. После кончины Ольги Арсеньевны по решению Правления ММО он стал главным редактором этого издания. При его непосредственном участии вышло 53 тома "Трудов". Он также был членом редколлегии журнала "Mathematische Nachrichten".

Работы Леонида Романовича Волевича составили крупный вклад в общую теорию уравнений с частными производными. Основы этой теории, восходящей к исследованиям классиков XVIII и XIX веков, были заложены в работах Ж. Адамара, С. Н. Бернштейна, И. Г. Петровского, Ж. Лере и С.Л. Соболева. Затем она была развита и продолжена в исследованиях М.И. Вишика, О. А. Ладыженской, Л. Ниренберга, О. А. Олейник, Л. Хёрмандера и других математиков.

Леониду Романовичу принадлежит глубокий анализ важнейших из этих работ и их развитие в новых направлениях. Для его творчества характерны также выявление 
общих проблем, стоящих за решением интересных конкретных задач, сбалансированность общности и глубины исследования.

В юбилейной статье в УМН (59:5 (2004), 175-182) описаны основные направления исследований Леонида Романовича и приведен список его избранных работ. Здесь мы кратко комментируем творчество Л.Р. и дополняем список его публикаций последними работами.

Отметим, что уже его первые работы [2], [6] о выделении старших частей систем уравнений в частных производных, отвечающих за локальные свойства решений, были высоко оценены Л. Гордингом и Ж. Лере, а введенные там условия определяют системы, получившие название систем Лере-Волевича.

Примерами удач в сочетании глубины и общности в исследованиях Л. Р. Волевича являются его работы по задаче Коши для дифференциальных операторов общего вида с переменными коэффициентами, работы по неоднородным гипоэллиптическим псевдодифференциальным операторам и по теории функциональных пространств.

Леонид Романович в течение 25 лет сотрудничал с С.Г. Гиндикиным, а их совместные результаты подытожены в трех монографиях.

Много внимания они уделили продумыванию работ И.Г. Петровского. Так, работа [20], посвященная сверточным уравнениям, возникла при анализе результатов Петровского для задачи Коши в области неаналитических функций. В ней выделены и на разных примерах проиллюстрированы структуры, ответственные за результаты подобного рода.

Одним из важных вкладов Л.Р. и С.Г. в общую теорию уравнений в частных производных было осознание факта, что многие результаты теории естественным образом формулируются в терминах многогранников Ньютона, связанных с символом оператора.

Первые результаты на эту тему были получены в работе [15], где этот многогранник еще назывался характеристическим. Там был выделен специальный класс гипоэллиптических операторов, определяемый по многограннику Ньютона (подобно тому как эллиптичность определяется по степени, а квазиэллиптичность по взвешенной степени символа). Этот класс содержит композиции $q$-квазиэллиптических символов с различными $q$. Он изучался многими авторами, и теперь эти операторы принято называть мультиквазиэллиптическими (см. также [62]).

Более трудной является решенная в [31], [40] задача описания операторов главного muпа, определяемых с помощью старшей и младших частей, ассоциированных с многогранником Ньютона. Для этого было построено разбиение единицы, ассоциированное с многогранником Ньютона. В этой сложной геометрической конструкции каждой грани многогранника отвечает область в сопряженном пространстве, в которой асимптотическое поведение многочлена определяется старшей квазиоднородной частью, отвечающей этой грани. В случае переменных коэффициентов при естественном предположении о вещественности старшей части получены априорные оценки и доказана локальная разрешимость соответствующих уравнений.

В последнее десятилетие Л. Р. вместе с немецкими математиками Р. Менникеном и Р. Денком успешно применял многоугольник Ньютона к задачам для общих систем, эллиптических по Дуглису-Ниренбергу, с большим параметром.

Проработав всю жизнь в ИПМ им. М. В. Келдыша, Л. Р. выполнил ряд вычислительных работ, в постановке которых непосредственное участие принимал К. И. Бабенко. Особого внимания заслуживает его исследование неустойчивости КельвинаГельмгольца [24], которое, к сожалению, опубликовано лишь в виде препринта ИПМ. Вычислительные работы проводились Л. Р. совместно с А. И. Аптекаревым, Н. Д. Введенской, Э. П. Казанджаном и в тесном контакте Ю. Б. Радвогиным.

Остановимся на последних работах Л. Р. В работе [62], написанной совместно с алжирским математиком Бузаром, введен и изучен общий класс гипоэллиптических 
систем уравнений в частных производных с переменными коэффициентами, обобщающих мультиквазиэллиптические уравнения.

В работе [63] рассматриваются общие граничные задачи, в которых как оператор в частных производных в области, так и граничные операторы полиномиально зависят от малого параметра. Определяются эллиптические и правильно эллиптические с малым параметром задачи. Доказывается, что эллиптичность с малым параметром необходима и достаточна для справедливости априорных оценок, равномерных по параметру. Вывод оценок основан на конструкции экспоненциального пограничного слоя, предложенной в работе М. И. Вишика и Л. А. Люстерника 1957 г. Исследование Л. Р. по существу является современным переосмыслением результатов этой классической работы.

В работе [64] дается детальное описание строго псевдогиперболических многочленов. Для псевдогиперболических уравнений в частных производных с постоянными коэффициентами выводятся априорные оценки и доказывается разрешимость задачи Коши.

В работе [65] для параболических операторов, не разрешенных относительно старшей производной по времени, рассмотрена смешанная задача с граничными условиями общего вида и нулевыми начальными условиями. Описан аналог условия Шапиро-Лопатинского, позволяющий в специально сконструированных функциональных пространствах получать двусторонние априорные оценки. Л. Р. обнаружил, что в этой задаче характеристическое уравнение в полупространстве имеет две группы корней с различной асимптотикой и в силу этого обстоятельства решающую роль в исследовании снова играет метод Вишика-Люстерника.

В работе [66] введен новый класс граничных задач для параболических операторов в частных производных. Обсуждаются некоторые линеаризованные задачи со свободной границей, не удовлетворяющие классическим условиям параболичности. Показано, что эти задачи входят в новый класс. При помощи многоугольника Ньютона для этих задач получены нетривиальные двусторонние априорные оценки решений.

Нет нужды объяснять, что эти работы идейно и тематически тесно связаны с предшествующими исследованиями Л.Р. и написаны на очень высоком математическом уровне.

Леонид Романович участвовал во многих международных конференциях и конгpeccax. В 2006 г. он был одним из двух приглашенных российских докладчиков на математической конференции в Бедлево, посвященной столетию Ж. Лере.

Не имея опыта систематического преподавания, Л. Р. несомненно обладал врожденным педагогическим даром, и его доклады на университетских семинарах, в математических школах и на конференциях всегда воспринимались с большим интересом.

Леонид Романович Волевич был глубоко порядочным, скромным, добрым и отзывчивым человеком; его характерными чертами были верность и надежность. Все его соавторы отмечают, что работать с ним было легко и приятно. Вообще, его чисто человеческие качества - открытость характера, оптимизм, поразительная эрудированность, общительность, доброжелательность, обаяние всегда привлекали к нему многочисленных друзей.

Для нас его уход из жизни - потеря не только интереснейшего математика, с которым мы имели возможность постоянно общаться, но и близкого товарища, и это невосполнимая личная потеря. Остались светлая память о нем и его работы, которые еще очень долго будут оставаться востребованными.

М.С. Агранович, А.И. Аптекарев, А.Л. Афендиков, Н. Д. Введенскал, М.И. Вишик, С. Г. Гиндикин, М.М. Маламуд, Б. П. Панеях, Е.В. Радкевич, В. М. Тихомиров, А.Р. Ширикян 


\section{Список избранных научных работ Л. Р. Волевича}

[62] "Hypoelliptic systems connected with Newton's polyhedron", Math. Nachr., 273:1 (2004), 14-28 (with Ch. Bouzar).

[63] "Метод Вишика-Люстерника в эллиптических задачах с малым параметром”, Тр. MMO, 67, УРCC, M., 2006, 104-147; англ. пер.: "The Vishik-Lyusternik method in elliptic problems with a small parameter", Trans. Moscow Math. Soc., 2006 (2006), $87-125$.

[64] "The Cauchy problem for hyperbolic equations not resolved with respect to the highest time derivative", Russ. J. Math. Phys., 13:3 (2006), 278-292 (with I. Fedotov).

[65] Метод Вишика-Люстерника в смешанной задаче для параболических операторов, не разрешенных относительно старшей производной по времени, Тр. ММО, 68, УPCC, M., 2007.

[66] "A new class of parabolic problems connected with Newton's polygon", Discrete Contin. Dyn. Syst., 2007, suppl., 294-303 (with R. Denk).

Начало списка см. в УМН, 59:5 (2004), 175-182. 